\title{
Surface Ultrastructure of Third-instar Megaselia scalaris (Diptera: Phoridae)
}

\author{
Kabkaew L Sukontason ${ }^{+}$, Kom Sukontason, Sirisuda Lertthamnongtham, \\ Noppawan Boonchu
}

\author{
Department of Parasitology, Faculty of Medicine, Chiang Mai University, Chiang Mai 50200, Thailand
}

We describe some ultrastructure of the third-instar Megaselia scalaris (Diptera: Phoridae) using scanning electron microscopy, with the cephalic segment, anterior spiracle and posterior spiracle being emphasized. This study provides the taxonomic information of this larval species, which may be useful to differentiate from other closelyrelated species.

Key words: Megaselia scalaris - ultrastructure - third-instar - scanning electron microscopy - forensic entomology

Megaselia scalaris (Loew), humpbacked fly, is an insect of medical importance worldwide. In addition to causing myiasis in humans (Trape et al. 1982, Singh et al. 1988, Singh \& Rana 1989), it has also been reported as a forensically-important fly (e.g. Barnes 1990, Disney 1994). Larvae of this species have more recently been reported from both exposed human corpses and within a tightly sealed corpse (Greenberg \& Wells 1998). Thus, the identification of this fly larva to species is mandatory to improve the accuracy of a forensic investigation, if this larva is present in a corpse and could be used as entomological evidence.

The immature and adult stages of $M$. scalaris have been previously described based on light microscopy (Zumpt 1965, Tumrasvin et al. 1977, Kaneko et al. 1978, Liu \& Greenberg 1989), and scanning electron microscopy (SEM) has been used to describe the egg (Greenberg \& Wells 1998). We report, herein, some details of the surface ultrastructure of the third-instar M. scalaris with the aid of SEM. Particular attention was given to the morphology of the cephalic segment, anterior and posterior spiracles, in order to point out some taxonomic significance from the other Megaselia species.

The third-instar $M$. scalaris, which was obtained from wild-caught females that came to lay eggs in a tray baited with fresh pork liver, was set up in the Department of Parasitology, Faculty of Medicine, Chiang Mai University, Thailand. The eggs were identified as M. scalaris according to the morphological features demonstrated by Greenberg and Wells (1998). Once the first-instar hatched

This work received support from the Faculty of Medicine Endowment Fund, Chiang Mai University.

${ }^{+}$Corresponding author. Fax: +66-53-217144. E-mail: klikitvo@mail.med.cmu.ac.th

Received 25 September 2001

Accepted 3 April 2002 from the egg, it was reared with fresh pork liver until reaching the third-instar. Some larvae were collected from the colony and washed several times with normal saline solution. They were killed by placing in hot water $\left(\approx 70^{\circ} \mathrm{C}\right)$ for a few min and then fixed in a fixative agent consisting of $2.5 \%$ glutaraldehyde at $4^{\circ} \mathrm{C}$ for $24 \mathrm{~h}$. The fixed larvae were then subjected to postfixation in $1 \%$ osmium tetroxide and dehydration in a graded alcohol series that was followed by treatment in acetone and critical-point drying. They were then mounted on stubs, sputter-coated with gold, and viewed with a JEOL-JSM840A scanning electron microscope. Photomicrographs were made using Kodak ${ }^{\circledR}$ Verichrome Panchromatic film VP 200.

The third-instar $M$. scalaris is creamy white and $\approx 4$ $\mathrm{mm}$ in length. The body is cylindrical and tapers toward the head (Figs 1,2). The integument is composed dorsally and laterally of short spinous processes (peglike processes; Liu \& Greenberg 1989). The cephalic segment is composed of a pair of dorsal organs ("antenna"), a pair of maxillary palp complexes and a mouthpart (Fig. 3). The antenna is dome-shaped with one cylindrical coeloconic sensillum placed laterally and centrally (Fig. 3). The maxillary palp complex consists of several types of papillae (Fig. 4). This could enable the larvae to have various receptors and, thus, perceive considerable information on their environs.

The prominent features of the mouthpart are the labrum, labium, a pair of mouth hooks and an oral groove (cuticular ridges associated with the mouth) (Fig. 5). A pair of sensillae is located ventrally at the end of the labrum. The labium is more or less a large triangular portion that is different from the tripartite feature of the other third-instar of the fly, Haematobia irritans (L.) (Baker 1987). Each mouth hook appears as a semi-circle lobe, with its rim composing of a $\approx 9$ deep serration (Figs 5, 6).

The anterior spiracles are located on each latero-posterior edge of the prothorax (Fig. 7). Each appears as ovalshaped, having two spiracular openings (slits), with one end closed together, while the other is far apart. A pair of 
posterior spiracles protrudes dorsally on the 12th segment (Fig. 8). Each appears as a large and slender spiracular plate, which is constricted centrally (Fig. 9). Each constriction is composed of two straight spiracular slits. The spiracular hairs appear centrally, at the area of constriction.
Zumpt (1965) has described some morphological features of three larval Megaselia species; M. scalaris, $M$. rufipes (Meigen) and $M$. spiracularis Schmitz, which are myiasis-producing flies. As for the flies that may associate in forensic investigations, only some phorid species
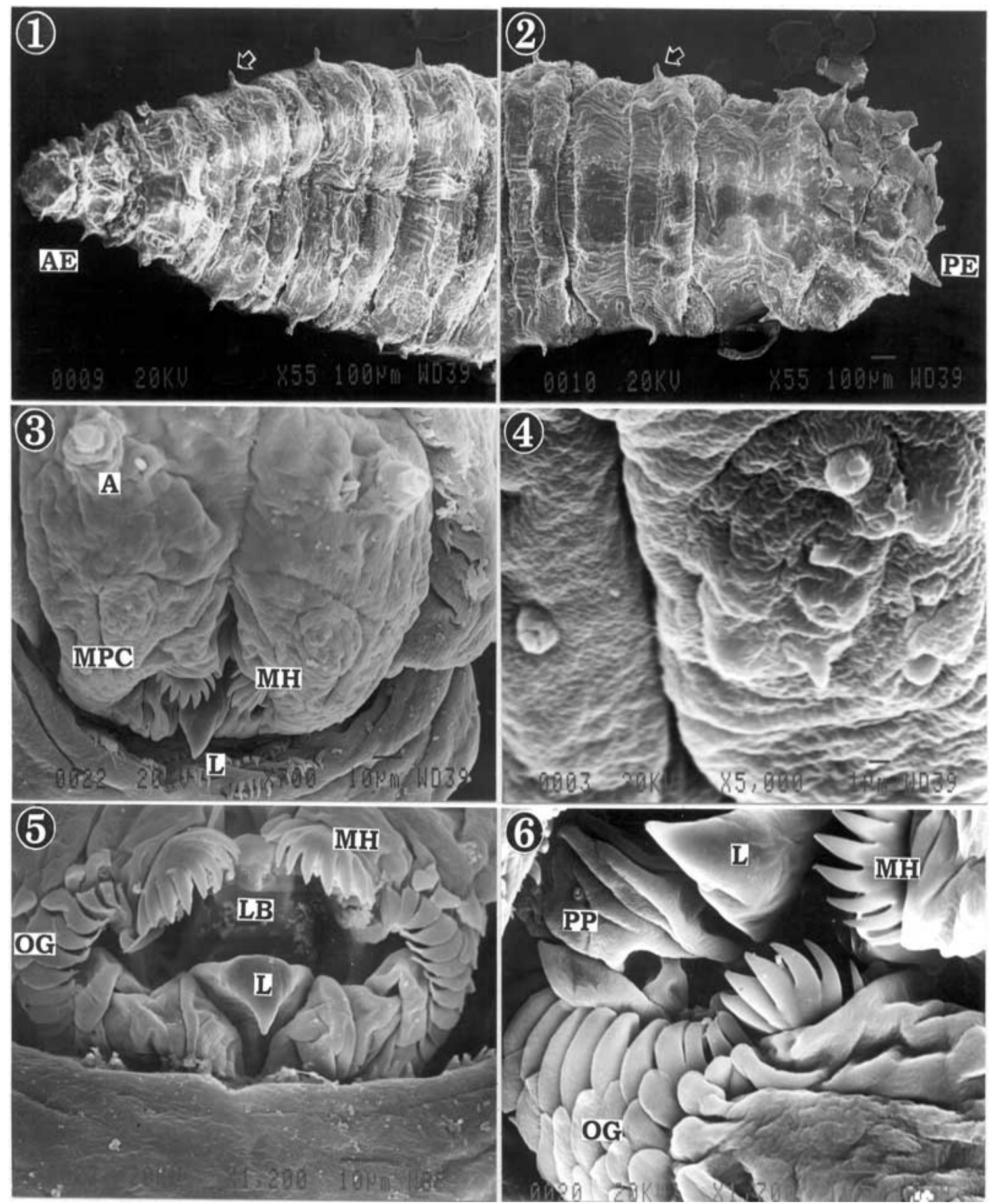

Scanning electron micrographs of the third-instar Megaselia scalaris. Fig. 1: the ventral view of the anterior end (AE) of the body. Fig. 2: the ventral view of the posterior end (PE) of the body. Arrows in Figs 1, 2 indicate short spinous processes. Fig. 3: apical view of the cephalic segment illustrating the antenna (A), maxillary palp complex (MPC), mouth hooks (MH) and labium (L). Fig. 4: higher magnification of the maxillary palp complex showing several types of papillae. Fig. 5: mouthpart showing mouth hooks (MH) with a deep serrated rim, labrum (LB), labium (L) and an oral groove (OG). Fig. 6: higher magnification of the mouthpart including a posterior pore $(\mathrm{PP})$. 

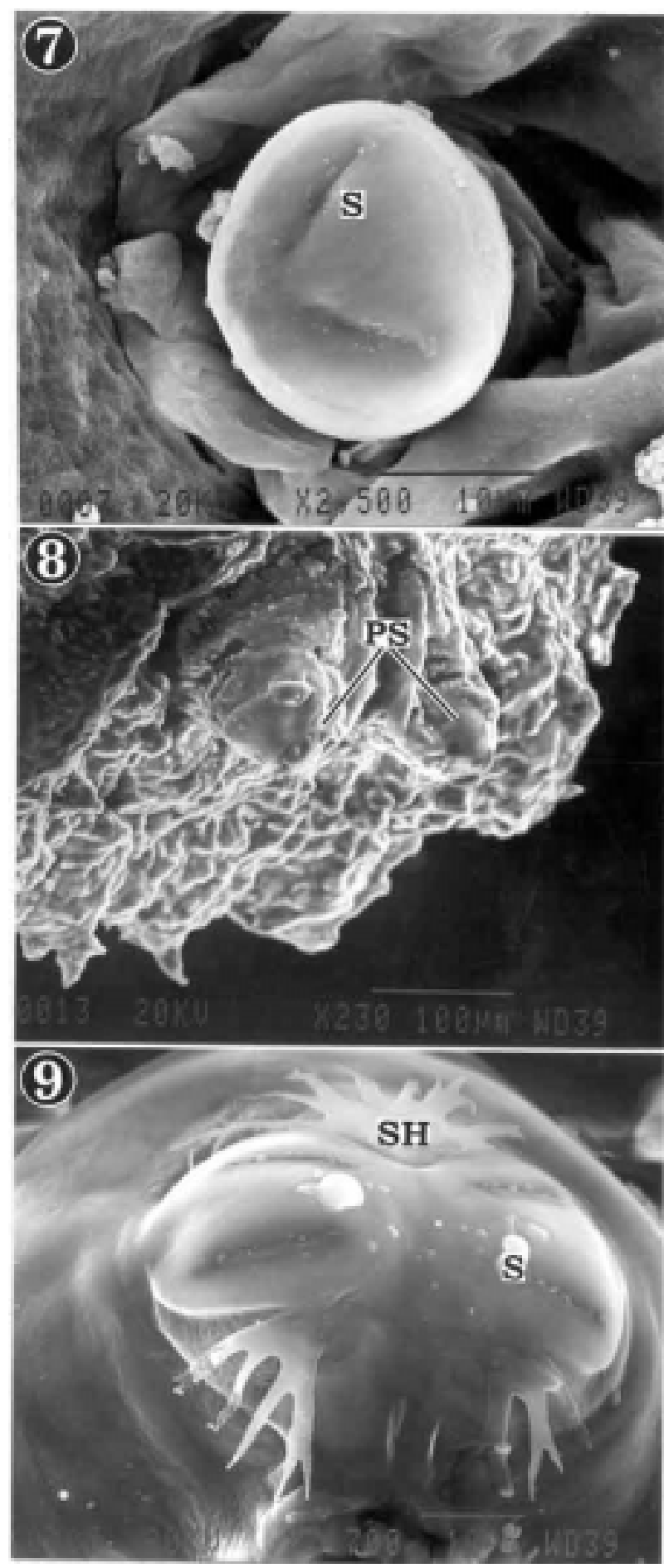

Scanning electron micrographs of the third-instar Megaselia scalaris. Fig. 7: anterior spiracle showing two straight slits (S). Fig. 8: postero-sagital view showing a pair of protruding posterior spiracles (PS). Fig. 9: apical view of the left posterior spiracle illustrating a slender spiracular disc that is constricted centrally. Two straight slits located on each side of its constriction. Spiracular hair (SH) that appears in the centre of the posterior spiracle. have been demonstrated (Smith 1986). This present study provides some taxonomic information of third-instar $M$. scalaris, which may be useful to differentiate from the other closely-related species.

\section{ACKNOWLEDGEMENTS}

To Dr RHL Disney, University of Cambridge, UK, for confirming identification. To Budsabong Kuntalue and Natchanart Thijuk for their technical assistance.

\section{REFERENCES}

Baker GT 1987. Morphological aspects of the third instar larva of Haematobia irritans. Med Vet Entomol 1: 279-283.

Barnes JK 1990. Life history of Dohrniphora cornuta (Bigot) (Diptera: Phoridae), a filth-inhabiting humpbacked fly. $J$ New York Entomol Soc 98: 474-483.

Disney RHL 1994. Scuttle Flies: the Phoridae, Chapman-Hall, London, $467 \mathrm{pp}$

Greenberg B, Wells JD 1998. Forensic use of Megaselia abdita and M. scalaris (Phoridae: Diptera): case studies, development rates, and egg structure. J Med Entomol 35: 205-209.

Kaneko K, Furukawa E, Kusui Y 1978. Studies on phorid flies (Phoridae, Diptera) in Japan. Part III. New record of Megaselia scalaris (Loew, 1866), collected from Japan. $J$ Aichi Med Univ Ass 6: 261-265.

Liu D, Greenberg B 1989. Immature stages of some flies of forensic importance. Ann Entomol Soc Am 82: 80-93.

Singh NB, Singh TK, Singh YI, Razaque MA 1988. Intestinal myiasis caused by Megaselia scalaris (Diptera: Phoridae): a case report. J Commun Dis 20: 163.

Singh TS, Rana D 1989. Urogenital myiasis caused by Megaselia scalaris (Diptera: Phoridae): a case report. J Med Entomol 26: 228-229.

Smith KGV 1986. A Manual of Forensic Entomology, Cornell University Press, Ithaca, $205 \mathrm{pp}$.

Trape JF, Vattier-Bernard G, Trouillet J 1982. A case of intestinal myiasis caused by larvae of Megaselia scalaris (Diptera: Phoridae) in the Congo. Bull Soc Pathol Exot Filiales 75: 443-446.

Tumrasvin W, Sucharit S, Vutikes S 1977. Studies on the life history of Megaselia scalaris (Loew) in Thailand. Southeast Asian J Trop Med Public Health 8: 74-76.

Zumpt F 1965. Myiasis in Man and Animals in the Old World, Butterworths, London, $267 \mathrm{pp}$. 
